\title{
Pretorianismo y etnicidad en la fachada atlántica: Surinam y Guyana (1968-1992)
}

Prof. Dr. Francisco Silva Ardanuy Universidad Pablo de Olavide (Sevilla, España)

Recibido: diciembre de 2013

Aprobado: agosto de 2014

Resumen: La antigua colonia británica de Guyana que alcanzó su independencia el 26 de mayo de 1966, sumiéndose dos años después en un Gobierno autoritario que se prolongó hasta 1992. Surinam fue sometida a un modelo de Estado pretoriano entre 1980 y 1991. Los paralelismos entre ambos Estados son evidentes y su coincidencia temporal explica el proceso de deslizamiento hacia gobiernos basados en el militarismo y el estado de excepción que se venía desarrollando en la región del caribe y países limítrofes. Analizar la naturaleza de ambos regímenes, su evolución y el papel que desempeñaron en su ámbito geográfico es el objeto del presente artículo.

Palabras clave: militarismo, pretorianismo, estado de excepción, fraude electoral, golpe de Estado, OEA, Surinam, Guyana, Trinidad y Tobago, partido único, socialismo, FMI, represión.

\section{Pretorianism and ethnicity in the Atlantic: Suriname and Guyana (1968-1992)}

Abstract: The former British colony of Guyana which achieved its
independence on 26 May 1966, sinking two years later in an authoritarian
Government which lasted until 1992. Suriname was subjected to a model of
Praetorian state between 1980 and 1991. The parallels between the two States
are evident and their temporal coincidence explains the process of sliding
towards Governments based on militarism and State of emergency that had
been developing in the region of the Caribbean and neighbouring countries. 
Analyze the nature of both regimes, their evolution and the role played in its geographical scope is the object of this article.

Key words: Militarism, pretorianism, state of emergency, electoral fraud, coup d'Etat, OEA, Grenada, Trinidad \& Tobago, single party, socialism, FMI, repression.

\section{1.- Introducción}

El pretorianismo, en una dimensión conceptual restrictiva, alude a la intervención de las Fuerzas Armadas en la vida política, sobre la base de una urgencia social que impulsa a los militares a tomar parte en los asuntos públicos que de otra forma le estarían reservados. La conformación de una sociedad "pretoriana" conjuga una sobre dimensión del papel de los cuerpos armados en la vida pública con una debilidad sistémica de las instituciones políticas, lo que genera no sólo una sociedad fragmentada sino un poder extraordinariamente atomizado. La autoridad sobre el sistema adquiere dimensión transitoria y la debilidad de las instituciones políticas nos traslada que es relativamente sencillo adquirir autoridad o un cargo de relevancia en este sistema. Los individuos son absorbidos por una fuerza social de intereses más estrechos que aquellos en quienes depositaban su lealtad. En las distintas etapas del pretorianismo las fuerzas sociales mantienen una interacción dialéctica entre sí, y hacen pocos o ningún esfuerzo para relacionar sus intereses personales con el bien público. En una oligarquía pretoriana la política queda reducida a una lucha intestina entre los cercanos al poder; en el pretorianismo radical, podemos encontrar confrontaciones directas entre los grupúsculos que disputan el poder y los grupos institucionales que operan dentro del sistema; en el pretorianismo de masas las clases y los movimientos sociales vienen a dominar de manera absoluta el contexto político y social. Cada tipo de sociedad pretoriana tiene por definición una duración que se relaciona con quién ejerce el control sobre la sociedad; mientras las oligarquías pretorianas pueden perpetuarse en el poder durante largos periodos, las oligarquías suelen tener dificultades para permanecer en la dirección política de sus sociedades más allá de unos años.

La intervención de las Fuerzas Armadas en la escena política suele ser la respuesta a un incremento gradual del conflicto social que se dé entre grupos o partidos. Por lo general dichas intervenciones no pretenden evitar el conflicto 
surgido de la tensión social, sino para detener la rápida movilización de las fuerzas sociales en el plano político o de la movilización de base. ${ }^{1}$

La aparición de las Fuerzas Armadas en la escena política se ha vehiculado por lo general a través de Golpes de Estado, como fórmula extrema que viene no sólo a modificar la política de un Gobierno, sino al Gobierno mismo. Es el medio que viene a poner fin a otro tipo de acciones contra la autoridad política, si bien su impacto contra la propia autoridad política es tal, en términos de restricción de derechos y libertades que el propio poder se transforma de manera integral.

Las primeras interpretaciones en relación al papel de los golpes de Estado de origen militar provienen de la década de 1970 a partir de la interpretación de los historiadores norteamericanos. Desde una versión liberal E.Lieuwen como en la visión desarrollista de John Johnson se partía de analizar la diferencia entre la sociedad tradicional frente a la sociedad moderna situando a las Fuerzas Armadas en un contexto de aislamiento de la formación social. Se afirmaba en ambos autores que la toma de iniciativas golpistas respondía a la necesaria toma del poder ante un vacío político existente en el país. Para desarrollar esta primera visión aportada por E.Lieuwen ${ }^{2}$ y John Johnson los autores Gino Germani y K.Silvert ${ }^{3}$ desarrollan un modelo de desarrollo del golpismo militar y su evolución de carácter unilineal en seis etapas:

1.-Revoluciones y guerras por la independencia nacional.

2.-Anarquía “Caudillismo” y guerras civiles.

3.-Dictaduras unificadoras.

4.-Democracia representativa con participación limitada.

1 Brian Loveman, For la Patria; Politics and the Armed Forces in Latin America, Wilmington Massachusetts, E. R. Books. 1999, pp.67-69.

2 Edwin Elieuwen, Armas y política en América Latina, Buenos Aires, Ed. Sur, 1960, p.19; John Johnson, Militares y sociedad en América Latina, Buenos Aires, Ed. Solar, 1966, pp.2431; Alain Joxé y Cecilia Cadena, El armamentismo de los países dependientes. El caso latinoamericano, en Estudios Internacionales n. ${ }^{\circ} 14$, Santiago de Chile, 1970; José Nun, América Latina: la crisis hegemónica y el golpe militar, Desarrollo Económico, Buenos Aires, 1966.

3 Virgilio Beltrán, El Papel Político y Social de las Fuerzas Armadas en América Latina, Caracas, Monte Ávila Eds., 1970; Gino Germani, y Kalman Silvert, Structure and military intervention in Latin America, European Journal of Sociology, Cambridge, 1961, pp.62-81 
5.-Democracia representativa con representación ampliada.

6.-Participación total a través de revoluciones "nacional populares".

Asimismo construyeron una tipología abstracta de las relaciones civiles militares:

1.-El Estado guarnición militar clásico.

2.-El Estado guarnición totalitario moderno.

3.-Las relaciones político-militares totalitarias.

4.-Los militares como gobernantes institucionalizados.

5.-Los militares-gobernantes fideicomisarios.

6.-Los militares como orientadores de la política nacional.

7.-Los militares como grupo de presión con poder de veto.

8.-Los militares como grupo de presión simple.

9.-Los militares como simple fuerza de policía completamente subordinada al Gobierno.

10.-Los militares como brazo político del Estado.

Partiendo de ambas tipologías la hipótesis sobre el por qué de los golpes militares en el contexto latinoamericano podría formularse así:

a) El golpismo es inherente a países con estructuras sociales duales fuertemente subdesarrollados.

b)La intromisión del poder militar en la estructura del poder político siempre indica, por supuesto, al menos una relativa incapacidad de otras instituciones sociales para manejar eficazmente su poder y a lo sumo, un estado avanzado de descomposición institucional.

c) Los militares serán reducidos a sus cuarteles y a sus funciones profesionales sólo cuando los países latinoamericanos desarrollen estructuras de poder suficientemente complicadas y una sociedad suficientemente flexible e integrada; cuando las discontinuidades sociales y geográficas hayan sido 
reducidas de manera notable y las masas aisladas o marginadas hayan sido incorporadas al cuerpo nacional; cuando los conflictos económicos y sociales hayan encontrado un modo de expresión institucionalizado dentro de un marco común de normas compartidas. ${ }^{4}$

Dicha teoría en relación al papel del golpismo militar en América Latina se vio modificada por la tendencia de las Fuerzas Armadas golpistas de permanecer en el poder una vez tomado el mismo y la sucesión de nuevos golpes que reaccionaban ante la usurpación del poder por parte de los militares. Así José E. Miguens ${ }^{5}$ afirmaba que la decisión de tomar el gobierno y las formas y modos de gobernar resultan de los aspectos estructurales de la organización y sus procesos internos, Su tesis guiada por la "Teoría de la acción" de Talcott Parsons ${ }^{6}$ le llevaba a considerar por un lado que los llamados "militares sociales" son originadores de su propio comportamiento y por otro lado el enfoque mecanicista según el cual el sector militar no solo tiene permanentes transacciones con los otros subsistemas, sino que todo cambio en uno de los subsistemas modificará los otros y el funcionamiento de la sociedad en general. Las Fuerzas Armadas no son objetos pasivos ni estáticos; por el contrario cambian constantemente al igual que la formación social global. Miguens explica el comportamiento político de los militares en términos de la agudización del conflicto de valores entre la "sociedad militar" y la "sociedad civil".

Para poder conocer en definitiva la actitud que los militares tomaran en la coyuntura política ante el vacío de poder o ante supuestos de "autoridad en crisis" debe observarse que el estado de la organización militar es una variable cuyas variaciones deben ser estudiadas a lo largo del tiempo, porque son un elemento fundamental para la explicación y predicción de su comportamiento político. Podría afirmarse que la alta modernización por una parte, tiende a

4 Morris Janowitz, Military Institutions and Coercion in Developing Nations, Chicago, Chicago University Press, 1977, pp.49-53.

5 Tulio Halperin Donghi, Historia contemporánea de América Latina, Madrid, Alianza Ed., 1969; José E. Miguens, "Una nueva metodología para el estudio de los golpes militares en Latinoamérica" en Estrategia, Buenos Aires, Ed. Eudeba, 1969; José Nun, América Latina: la crisis hegemónica y el golpe militar, Buenos Aires, Desarrollo Económico, 1966.

6 Tiene su origen en la obra de Max Weber sobre la acción social. Parsons escogió el término acción porque tenía una connotación diferente a la de conducta. Conducta implica una respuesta mecánica a los estímulos, mientras acción entraña un proceso mental activo y creativo. Parsons tuvo la precaución de distinguir explícitamente la teoría de la acción del conductismo .En Talcott Parsons, Robert F. Bales y Edward A. Shils, Apuntes sobre la teoría de la acción, Buenos Aires: Ed. Amorrortu, 1970. 
resultar en pretorianismo ${ }^{7}$ de masas y, por otra, a introducir cambios "profesionalizantes" en la organización militar. Estos últimos, a su vez, determinan cruciales cambios en los medios y objetivos con los que los militares intentan actuar sobre el contexto social del que son parte. En una primera etapa, las preocupaciones centradas en la propia organización militar inducen un exitoso esfuerzo de profesionalización. En una segunda etapa, la misma motivación contribuye a la ejecución de un Golpe de Estado, que inaugura un tipo "burocrático" de autoritarismo político característico de las naciones altamente modernizadas que han sufrido un periodo de pretorianismo de masas. Este golpe de Estado un grado de participación política de los militares y de militarización de los problemas sociales que exceden en mucho todo lo que pudo haber sido intentado por oficiales pertenecientes a una institución escasamente profesional. Por lo tanto, en condiciones de alta modernización, tiende a ser logrado un grado relativamente alto de profesionalización militar.

Todas las interpretaciones mencionadas tienen en común una serie de supuestos;

a) El dualismo sociedad tradicional-sociedad moderna.

b) La noción compartimentada del poder político.

c) El supuesto de que existe una contradicción entre civiles y militares.

d) El supuesto de que la institución militar, con sus valores específicos, esta parcial o totalmente aislada de la formación social.

e) El supuesto de que se pueden comparar los golpes militares en abstracto sin distinguir lugares ni momentos históricos.

\footnotetext{
7 El pretorianismo emerge cuando los niveles de participación y movilización política exceden marcadamente de la institucionalización política. En un sistema social pretoriano las fuerzas sociales se enfrentan entre sí; No hay instituciones políticas ni un cuerpo de dirigentes políticos profesionales que sean reconocidos como intermediarios legítimos para la moderación de los conflictos grupales. No existe acuerdo entre los grupos sobre los medios legítimos y autoritarios para resolver conflictos. En una sociedad pretoriana, sin embargo, no sólo son diferentes los actores, sino también los métodos para decidir sobre la ocupación de posiciones gubernamentales y sobre la adopción de políticas públicas. Cada grupo social emplea los medios que refleja su naturaleza existiendo por tanto en la sociedad pretoriana un poder militar, un poder sindical, un poder estudiantil etc. En esta sociedad dicho poder militar tendrá una función manifiesta; la defensa nacional y una función latente; la defensa de los interese de la "clase media" de la que provienen sus cuadros. Luis A. Costa Pinto, Nacionalismo y militarismo, México, Ed. Siglo XXI, 1970.
} 
f) La ausencia de la dependencia como variable explicativa y del contexto de expansionismo militar mundial.

g) La supuesta contradicción "totalitarios-democráticos" en la cual se asigna el rol de agente democrático a la sociedad civil frente a los agentes militares que se inscribirían en un rol totalitario.

En el marco del dualismo "sociedad tradicional-sociedad moderna" las sociedad cubana pertenecería, siguiendo el esquema anteriormente señalado de Germani-Silvert, a la "sociedad tradicional" aunque en tránsito modernizador que le llevaría en la década en la antesala de los procesos de descolonización a un modelo social dual en la que convivían la vieja oligarquía de las metrópolis y las nuevas compañías extranjeras que empezaban a operar en ambos Estados. ${ }^{8}$

En segundo lugar, la compartimentación del poder político, consecuencia inevitable del dualismo estructural, originará de manera sucesiva periodos de "vacío de poder" derivados de la "indecisión social" marco aprovechado por las Fuerzas Armadas para consolidar su posición preeminente dentro de una frágil estructura social . La debilidad institucional apreciada por la oficialía militar ha llevado históricamente a concluir a una mitigación de la inestabilidad mediante una asonada golpista derivada de los planteamientos realizados en el seno de las Fuerzas Armadas que consideran que la inestabilidad sólo hace peligrar su papel preponderante dentro de la sociedad, poniéndose al tiempo en riesgo sus intereses como cuerpo.

En relación a la contradicción "civiles-militares", esta suele ser observada como el centro del problema de los Golpes de Estado de origen militar en tanto se entiende dicha contradicción desde una visión de "suma cero"; es decir, en la medida que aumenta el poder militar disminuye el poder civil. En la escena política caribeña aparece de manera reiterada una contradicción entre las Fuerzas Armadas y los partidos políticos (poder civil).Pero no podemos afirmar que existan los "civiles" en abstracto, de la misma forma que no existen los "militares" en abstracto. Existen los partidos políticos y los movimientos cívicos por un lado y las Fuerzas Armadas-aparato represivos del Estado por otro. ${ }^{9}$

8 Manuel Diez Alegría, Ejército y Sociedad, Madrid, Ed. Alianza, 1972.

9 V. Rafael Beltrán, El Papel Político y Social de las Fuerzas Armadas en América Latina; John Johnson, Militares y Sociedad en América Latina, Buenos Aires, Eds. Solar Hachette, 1966; Charles Moskos Jr. \& G. H. Jenkens, Las Fuerzas Armadas y la Sociedad. Madrid, Alianza Universidad, 1984; Alain Joxé y Cecilia Cadena, "El armamentismo de los países dependientes. El caso latinoamericano", en Estudios Internacionales n. $^{\circ} 14$, Santiago de Chile, 1970. 


\section{El deslizamiento hacia sociedades militarizadas de la facha atlántica no hispánica: Surinam y Guyana (1968-1992)}

Guyana y Surinam han vivido procesos históricos muy similares en las últimas décadas en lo que ha tránsito hacia sistemas democráticos se refiere. Entre 1968 y 1992, Guyana vivió bajo un régimen autoritario dirigido por el Congreso Nacional del Pueblo (Peoples National Congress) que presidía Lindon Forbes Sampson Burnham, quien apoyó su control social en procesos electorales fraudulentos y un amplio sistema de fuerzas de seguridad. En Surinam, en 1980, cinco años después de la declaración de independencia de Países Bajos, el Primer Ministro Henck Arron fue derrocado por un Golpe militar, que impuso en el país un modelo de organización que se prolongaría hasta 1991, donde las Fuerzas Armadas se reservaban amplias competencias en la ordenación de la vida política, social y económica de la ex colonia holandesa.

En ambos Estados, el mantenimiento el modelo pretoriano de organización implicó enormes costos que conllevaron una profunda recesión económica, lo que condicionó el desarrollo de ambos Estados caribeños durante más de una década. Fue precisamente la necesidad de apoyo financiero internacional ante el deterioro social que vivían las ex colonias lo que flexibilizó la posición de los dos regímenes. Esta posición de apertura desembocó en la convocatoria de elecciones libres y multipartidistas respondiendo a la demanda social de ambas sociedades. ${ }^{10}$

A diferencia de Guayana. Surinam tuvo que enfrentar la aparición de grupos guerrilleros que opusieron resistencia armada lo que acrecentó el descalabro económico del gobierno militar, quién presionado intensamente por sus aliados en la escena internacional, se vio forzado a buscar acuerdos con los partidos políticos existentes

Para 1991, tras la desaparición del conjunto de Estados socialistas de Europa Oriental y con el impulso dado por la Administración estadounidense al establecimiento del hemisferio norte como zona de paz (lo que incluía un plan especial de pacificación del área centroamericana y caribeña), los regímenes militares del Sur del Caribe se habían convertido en un problema manifiesto. Los sucesos de Haití en 1991, en la que el Gobierno electo de Jean-Bertrand

10 Paul H. Lewis, Autoritarian regimes in Latin America; Dictators, despots and tyrants, Anse Books. Rowman \& Littlefield Publishers Inc. 2006, pp.11-13 
Aristide fue derrocado por un golpe militar encabezado por el general Raoul Cedrás, precipitaron la caída de los regímenes militares de Guyana y Surinam dando paso a unas elecciones libres. ${ }^{11}$

\subsection{Guyana y la necesaria sujeción del Ejército}

La Fuerza de Defensa de Guyana (GDF), como se denomina a las Fuerzas Armadas del país, surgieron inicialmente como una fuerza policial denominada Unidad de Servicios Especiales (SSU), creada en 1964 por las autoridades británicas, como un refuerzo a las unidades policiales, si bien ya se asumía a mediados de la década de los sesenta que dicho cuerpo estaba llamado a ser el origen de unas futuras Fuerzas Armadas. ${ }^{12}$

En su origen la GDF era una fuerza étnicamente equilibrada, donde la mitad de la tropa y los oficiales era de origen hindú. Su comandante era el oficial hindú entrenado de Sandhurst (Reino Unido), mayor Ramon Sattaur. ${ }^{13}$

Sin embargo, tras los comicios presidenciales de 1964, aún bajo dominación británica, el presidente Forbes Burnham rompió el principio de equilibrio étnico, impulsando unas Fuerzas Armadas (en un principio conformado por unos 600 efectivos) conformada y dirigidas mayoritariamente por negros ${ }^{14}$. Para 1970, la representación de afro-guyaneses en el ejército se había elevado en un 90\% en lo relativo a alistados, y en un 95\% en el cuerpo de oficiales. Dicha configuración de las Fuerzas Armadas respondía al intento del PNC que generar una identificación entre su programa político y sus líderes con la base de las Fuerzas Armadas del país, que estaban llamadas a jugar un importante papel en el bloqueo de las instituciones democráticas y permitir la imposición de protocolos autoritarios por parte del Congreso Nacional del Pueblo (PNC).

11 Samuel Huntigton, "New contingencies, old rules", in Joint Force Quarterly. Professional Military Journal, ${ }^{\circ} 3$, Autumn, 1991.

12 Puede entenderse que el impulso a la conformación de una Unidad de Servicios Especiales deriva del incremento de tensión fronteriza con la vecina república de Venezuela, que bajo el Gobierno de Rómulo Betancourt aumentó la presión sobre los límites territoriales venezolanos.

13 Chaitram Singh, "Ethnic Guardians: The Role of the Military in Guyana's Politics", in The Journal of Developing Societies, vol.IX, 1993.

14 El primer comandante negro de la Fuerza de Defensa de Guyana fue el Mayor afro-guyanés Clarence Price. 
El establecimiento de un régimen militar en Guyana fue alcanzando su implantación a través de procesos superpuestos. Para 1968 Forbes Burnham impulsó un proceso de fraude electoral que le permitió neutralizar a la emergente mayoría de origen hindú que se aglutinaba en torno al Partido Popular del Progreso (PPP) liderado por Cheddi Jagan. De este modo, el Partido Congreso Nacional del Pueblo (PNC) conseguía, manteniendo el aspecto formal de elecciones libres, alcanzar el poder en los comicios de 1968, revalidando su dominio electoral en 1973, 1980 y 1985 así como el proceso de referéndum organizado para refrendar el texto constitucional de 1978. Se establecía así un régimen de Partido único "de facto" representado ante la ciudadanía con una apariencia legítima. Lo único que variaba de un proceso electoral a otro era el reparto de escaños entre el PNC y el PPP de Jagan, quien prestándose de manera activa o pasiva a la operación de Forbes Burnham legitimaba el dominio omnímodo y la política autoritaria del PNC de la escena política guyanesa.

De manera paralela al amaño electoral que se venía perpetrando desde 1968, La Fuerza de Defensa de Guyana (GDF), eran un resorte esencial en las acciones del PNC. En este sentido, se hacía necesario un control férreo sobre la oficialía y los cuadros de mando que se ejercía mediante la purga periódica de oficiales, impulsando la promoción sistemática de oficiales negros frente a otros contingentes étnicos. En este sentido, los dirigentes del PNC de Burnham habían asumido la necesidad de no crear una identidad asentada entre los militares negros, para evitar un escenario en el que una eventual cúpula militar negra terminara derrocando a un poder ejecutivo negro, como había ocurrido en algunas repúblicas africanas en el marco del proceso de descolonización.

Tuvieron que producirse los sucesos de Trinidad y Tobago de 1970 para que el PNC entendiera el riesgo que conllevaba seguir otorgando poder a la Fuerza de Defensa de Guyana. ${ }^{15}$ Para mantener bajo su tutela a la GDF, Burnham impulsó la creación del Cuerpo de Educación en el ejército que se ocuparía del adoctrinamiento y la instrucción político-militar de los civiles al servicio de las Fuerzas Armadas y de los alistados. ${ }^{16}$ De manera paralela su puso fin a la

15 A principios de 1970, Trinidad y Tobago padeció una aguda crisis económica y social que generó serios disturbios raciales provocando varias muertes e innumerables daños; tras los incidentes producidos en las calles de las principales ciudades trinitienses, el Ejército dio un Golpe de Estado, lo que llevó al Primer Ministro Eric Williams a anunciar la creación de una Comisión sobre la Discriminación racial, si bien el Estado de emergencia nacional decretado se mantuvo hasta junio de 1972, momento en el cual se restableció el orden bajo el mandato de Williams que seguiría presidiendo Trinidad hasta 1981.

16 Margaret Daly Hayes, “¿Cuáles son los interrogantes?. Educación en civiles en Seguridad y Defensa”, en José Olmeda, Democracias frágiles, las relaciones civiles-militares en el mundo 
práctica de formar cadetes en academias extranjeras, especialmente en academias estadounidenses, al tiempo que se endurecían los requisitos de acceso en las Fuerzas Armadas (siendo uno de los requisitos exigibles la identificación o militancia con el PNC de Burnham, quien además de líder del PNC era Ministro de defensa y Presidente de la Junta de Defensa de Guyana que se ocupaba del control de los nuevos ingresos en las filas de la GDF).

Sin embargo, la creación de mecanismos de control interno que limitaran en el medio plazo la influencia de la cúpula militar sobre el Gobierno Burnham no era suficiente, por lo que se hacía necesario crear contrapesos organizados a la Fuerza de Defensa de Guyana. Así, se impulsó la creación del Servicio Nacional de Guyana, que se creó como fuerza expedicionaria de frontera que permitiera extender el control del Gobierno guyanés sobre la totalidad del territorio nacional y comenzar a acantonar tropas ante una eventual penetración de las Fuerzas Armadas venezolanas en el marco de la disputa territorial y fronteriza que sostenían Caracas y Georgetown. En apenas cinco años, En Servicio Nacional de Guyana (GNS) había alcanzado en términos de organización y número de efectivos a las tropas del GDF, si bien las nuevas tropas de Burnham contaban con un nivel de capacitación doctrinal mucho más alto. ${ }^{17}$

Junto a estos dos cuerpos profesionalizados (GDF y GNS) surgió en 1976 la "Milicia del Pueblo de Guyana" (GPM) que, a modo de Milicias Nacionales Revolucionarias, venían a cumplir la misión de incorporación de la masividad a los esfuerzos defensivos que el país venía organizando desde 1974 ante las permanentes disputas territoriales con Venezuela. Para este momento, Guyana, con una población estimada de 722.000 habitantes, contaban con 7000 efectivos armados. ${ }^{18}$

Iberoamericano, Valencia, Tirant Lo Blanch, 2005.

17 Si bien el GDF siguió siendo la fuerza más competente en términos de operatividad, la irrupción de las dos nuevas organizaciones armadas vino a romper la ecuación de relaciones bilaterales GDF-PNC, introduciéndose una cerrada competencia para la asignación presupuestaria anual correspondiente a cada cuerpo armado.

18 Carlos Celis Nogueras, Geopolítica regional; el área del Caribe, área andina y área amazónica, Caracas, Presidencia de la República, 1994, pp.24-31. 


\subsection{El proyecto político del PNC en Guyana}

Tras las elecciones de 1968 ganadas por el PNC, Forbes Burham presentó públicamente el modelo político para Guyana bajo el epígrafe de "socialismo cooperativo" que pretendió dar cobertura a un severo proceso de nacionalizaciones y expropiaciones puesto en marcha desde 1965 y que puso bajo el control estatal las industrias de procesamiento del azúcar y de la bauxita, así como de los medios de comunicación y de las hasta entonces escuelas privadas dirigidas por la Iglesia. Ocho años después, los dirigentes del PNC afirmaban haber llevado la estatalización de la economía guyanesa hasta el 80\%.

El Gobierno de Burham a pesar de una mejora explícita de sus relaciones con los países cercanos al Bloque del Este, se decantó por el no alineamiento y proclamó en 1970 la República Cooperativa de Guyana. Al mismo tiempo, impulsó la integración a través del CARICOM (Comunidad del Caribe), el Sistema Económico Latinoamericano y del Caribe (SELA) así como en la Flota Mercante del Caribe.

El proceso de hegemonización del PNC de la dimensión económica corrió paralelo al de la esfera política. En 1974, un año después de las elecciones presidenciales, Burham reclamaba para Guyana un modelo de partido con amplias atribuciones, a imagen del Partido Comunista de Cuba, convertido en partido único de la revolución socialista cubana el 3 de octubre de 1965. En la llamada "Declaración de Sophia" del 14 de diciembre de 1974, Burnham expresaba que tras la independencia de Guyana, el CNP había impulsado la construcción del socialismo frente a las posiciones del PPP de Cheddi Jagan:

Después de la independencia de Guyana, evidentemente la coalición comenzó a desintegrarse. Esto era inevitable porque nuestro socio de coalición era esencialmente un grupo capitalista y nosotros somos socialistas [...]. Por otro lado, el CNP hizo hincapié en el pueblo, en el proletariado y en el campesinado empobrecidos de quienes sacó y saca su poder. ${ }^{19}$

19 L. F. S. Burnham, Declaration to Sophia. 14 de Diciembre de 1974. Georgetown, GPL, 1974, pp.8-9. Constitution of the Co-operative Republic of Guyana, Georgetown, Guyana National Lithographic Co. Ltd., 1980. 
El Congreso del PNC celebrado en Georgetown en 1974 sancionó definitivamente la fusión de los poderes del Estado y del partido político, lo que posteriormente fue trasladado a la nueva Constitución de orientación socialista que fue aprobada en referéndum en 1978 entrando en vigor en 1980 de manera definitiva. ${ }^{20}$

Los avances desplegados por el Gobierno autoritario de Burnham le había permitido alcanzar un alto nivel de prestigio entre el conjunto de Países No Alineados, lo que en cierta manera le facilitaba que las violaciones sistemáticas de los derechos civiles y políticos de los guyaneses fueran obviados. La alta proyección interior y exterior de Burnham llevó incluso a un cambio en la posición política del PPP, quien, temiendo quedar fuera del proceso de acceso al socialismo abierto en el país, configuró la llamada doctrina del "apoyo crítico" al Gobierno del PNC, ${ }^{21}$ lo que sin duda facilitó el acceso del PNC a las bases militantes del partido de Jagan generando una transferencia de guyaneses de origen hindú hacia las posiciones de Burnham, rompiendo así el control que sobre dicho grupo étnico había mantenido hasta entonces el PPP.22

En 1980, Forbes Burnham fue reelegido presidente bajo la sombra del fraude electoral, mientras se producía un serio agravamiento de las condiciones económicas de un país que situaba su deuda externa en los 1560 millones de dólares. Esta situación abocó al Gobierno del PNC a establecer conversaciones con el Fondo Monetario Internacional (FMI) para lograr un crédito para hacer frente a sus obligaciones básicas. La no concesión del crédito por el FMI y la caída de los precios, y las materias exportables por Guyana llevó a la concesión de licencias de explotación a operadores privados de los yacimientos de petróleo y uranio.

La tensión económica su sumaba a una escalada de violencia en las principales ciudades guyanesas, siendo especialmente relevante el atentado con coche bomba contra el líder de la Alianza del Pueblo Trabajador (WPA) Walter Rodney.

20 L. F. S. Burnham, Economic Liberation through Socialism, Georgetown, Guyana Printers Ltd., 1977.

21 Cheddi Jagan, Critical Support, Straight Talk, 14 Septiembre, 1975.

22 Excepción hecha del conjunto del movimiento obrero organizado del sector del azúcar que seguía hegemonizado por el PPP, lo que le permitió en determinados momentos ejercer presión sobre el Gobierno de Georgetown mediante huelgas sectoriales. 
En 1984 las tensiones Guyana condeno el proceso de ocupación militar por parte de Estados Unidos de la isla de Grenada lo que, además de cerrarle el acceso a vías de financiación a través de organismos internacionales, situó a Guyana en la órbita de influencia soviética. ${ }^{23}$

En un escenario de profunda inestabilidad interna, y con crecientes tensiones en el gubernamental PNC se produce la muerte de Forbes Burnham quien sería sustituido al frente del ejecutivo y del Partido por Desmont Hoyte, quien volvería a ganar unas elecciones nuevamente señaladas por los organismos internacionales como fraudulentas.

Ante el empeoramiento del clima económico y político del país, cinco de los seis partidos de la oposición conformaron la llamada "Coalición Patriótica por la Democracia" lo que les permitió conformar una mayoría parlamentaria sólida. La respuesta del PNC, dominador de la escena política guyanesa desde la década de los setenta fue una actualización de llamado "socialismo cooperativo" que para aquel momento había demostrado su ineficacia ${ }^{24}$.

El desgaste político y la creciente presión social frente al modelo autoritario del PNC hizo derivar al país hacia un estado de emergencia que fue declarado en 1991 y que se mantuvo hasta junio de 1992. En este contexto y con una mayor presión por parte de los Estados Unidos y de las organizaciones regionales para la apertura democrática de Guyana, las elecciones presidenciales del 5 de octubre de 1992 otorgaron la victoria a Cheddi Jagan por el $54 \%$ de los votos frente al $41 \%$ de los votos obtenidos por Hoyte.

En 1993, el Gobierno de Jagan permitió el acceso de las tropas estadounidenses para que realizaran maniobras de entrenamiento en espacios de operaciones selváticos a cambio de recibir apoyo para desarrollar infraestructuras civiles en el interior del país y mejorar los sistemas de lucha contra el narcotráfico.

23 En el periodo 1976-1991, el PIB se redujo un 28\%, lo que se sumaba a una crisis monetaria severa ante la falta de divisas lo que limitó la capacidad importadora del Gobierno restringiéndose así la entrada de productos de primera necesidad para la población.

24 World Bank, Guyana: A Framework for Recovery, Washington D. C., The World Bank, 1985 . 


\subsection{La diplomacia del "socialismo cooperativista". La escalada de tensión con la Administración norteamericana}

La política exterior de Guyana desde 1966 fluctuó desde la equidistancia entre los contendientes de la "Guerra Fría" a la adquisición de compromisos en unas ocasiones con las posiciones del Bloque del Este y otras ocasiones con las autoridades de Washington, dependiendo de la frágil coyuntura política en la vivía instalado el Estado guyanés.

Entre 1967 y 1970, el Gobierno del PNC mantuvo una política exterior abiertamente pro occidental que fue reorientada en apenas dos años hacia la asunción de las tesis "tercermundistas". El Gobierno de Burnham paso de no reconocer a la República Popular China (y por tanto reconocer sólo a Taiwan) a pedir su inclusión en la ONU. En abril de 1971 se establecieron relaciones diplomáticas con la URSS a pesar del declarado "No alineamiento" de Guyana. El nuevo status de relaciones entre el Gobierno de Georgetown y el de Moscú provocó el enfriamiento y las primeras tensiones con los Gobiernos británicos y estadounidenses, al tiempo que reavivaba la tensión fronteriza con Venezuela que activó su reclamación histórica con la región de Asequibo.

Guyana estuvo presente en la III Cumbre de Países No Alineados celebrada del 8 al 10 de septiembre de 1970 en Lusaka (Zambia). En dicha Cumbre Guyana apoyó, junto a los 54 países miembros, dos declaraciones políticas; la denominada "Declaración sobre la paz, la independencia, el desarrollo, la cooperación y la democratización de las relaciones internacionales" y un segundo texto relativo a la "no alineación y el progreso económico" donde se fijaban las normas de cooperación económica entre los países miembros, y las bases para el desarrollo de la cooperación regional.

En 1971, el Gobierno del PNC aprovechó su asistencia a la Conferencia de ministros de la Commonwealth, celebrada en Singapur para estrechar lazos con las autoridades de la India de cara a afianzar el apoyo de sus tesis por parte de la población indo-guyanesa.

Durante el periodo que transcurrió entre 1972 y 1976, Guyana acompasó su cercanía con las autoridades soviéticas para iniciar un vasto programa de cooperación con Cuba. Dichas relaciones alcanzaron su punto más alto a partir del reconocimiento por parte del Gobierno de Georgetown del Gobierno 
revolucionario de Angola que encabezaba el líder del MPLA Agostinho Neto y la puesta a disposición para tareas logísticas del aeropuerto de Timehri a las Fuerzas Armadas cubanas que participaban en la la llamada "Operación Carlota”25.

En marzo de 1971, el Gobierno guyanés aprobó la llamada "Bauxite Nationalisation Act" y en julio de ese mismo año se procedió a la adquisición de la Compañía Canadiense de Aluminio (ALCAN) por la cantidad de 53.5 millones de dólares.

En 1972, el Gobierno procedió a la nacionalización de la "Guyana Timber Ltd." Un año después pasaron a titularidad estatal todas las tierras cultivables que no estuvieran en uso. En 1975 se procedió a la nacionalización de la "Reynolds Guyana Mines" y de la "Jessel Holdings". Finalmente en 1976, el Gobierno de Burnham nacionalizó la Compañía azucarera "Bookers Bros McConnel" a cambio de una compensación pactada de 70 millones de dólares. ${ }^{26}$

La tensión con la Administración norteamericana fue dirimida en terceros espacios como los organismos internacionales de crédito o en los organismos de cooperación regional, en la cual Guyana, a través de su vacilante política exterior, mantenía disensiones ciertamente acordadas con Washington, al tiempo que mantenía su apariencia revolucionaria formal.

La invasión estadounidense de Grenada tras la caída del Gobierno de Bishop llevó a las autoridades de Georgetown a una actitud más prudente con el vecino norteamericano. Habría de ser la presión combinada que organismos como el FMI y la Administración norteamericana dirigida por el demócrata Bill Clinton quienes forzaran finalmente la convocatoria de elecciones libres bajo control de observadores internacionales las que pusieran fin al gobierno autoritario del PNC y al fallido intento de construir una vía propia de acceso al socialismo en Guyana.

25 David R. Mares, Violent peace; Militarized interstate bargaining in Latin America, New York, Columbia University Press, 2001, pp.33-42.

26 Congress National Party, For socialism in Guyana. Political program of the People's Progressive Party, Prague, Orbis Press Agency, 1982, pp.70-74. 


\section{Surinam: de la colonia extractiva a la dictadura militar}

El 25 de febrero de 1980, dieciséis suboficiales comandados por el sargento mayor Desiré Delano Bouterse, iniciaron un Golpe de Estado contra el Gobierno presidido por el Primer ministro Henck Arron. En apenas veinticuatro horas, los golpistas rindieron los cuarteles de las Fuerzas Armadas, la Policía y el Gobierno ${ }^{27}$.

El llamado "Golpe de los sargentos" se configuró como la respuesta al grave deterioro económico y la convulsa situación social generada a raíz de la proclamación de la independencia de Surinam de los Países Bajos el 25 de Noviembre de 1975 y de la salida del 33\% del éxodo en dirección a la antigua metrópoli de al menos el $33 \%$ de la población surinamesa. ${ }^{28}$

Un contexto de parálisis parlamentaria, donde se producía enfrentamiento cada vez mayor entre los partidos políticos representados en el Staten (parlamento) llevo la oficialía surinamesa a subvertir el papel subordinado que tenía asignado e intervenir la escena política del país. ${ }^{29}$

La privatización de los yacimientos de bauxita, única materia prima exportable, llevó al antiguo instructor deportivo de las Fuerzas Armadas "Desi" Bouterse a alzarse en armas y deponer el Gobierno de Arron. El 15 de agoto de 1980 se constituyó el Consejo Militar Nacional que mantuvo como primer Ministro a Chin a Sen del Partido Nacionalista Republicano (PNR).

Las diferencias étnicas, lingüísticas y culturales de Surinam habían sido factores cruciales en la dificultad de conformación de una verdadera conciencia nacional unitaria. Por un lado se situaban el Partido representante de la población criolla, el National Partij Kombinatie (NPK) que acabaría

27 Gary Brana-Shute, "Back the Barracks? Five years "Revo" in Suriname", in Journal of Interamerican Studies and world Affairs vol.28, n. ${ }^{\circ} 1,1986$, pp.1-15.

28 Los acuerdos por el que se concedía la independencia la antigua Guyana Holandesa acompañaban de un generoso apoyo económico brindado por el Gobierno holandés que transfería 1960 millones de dólares de la época al nuevo Gobierno de Paramaribo. Betty Sedoc Dahlberg, "Interest Groups and the Military Regime in Suriname", in Alma H. Young and Phillips Dion (eds.), Militarization in the Non-Hispanic Caribbean, Boulder, Lynne Rienner Publishers, Inc., 1986.

29 Para 1980 las Fuerzas Armadas aún se encontraban bajo la tutela operativa de las Fuerzas Armadas neerlandesas. 
convirtiéndose en el Partido Nacional de Surinam; el Vatan Hitkarie que aglutinaba los intereses de la población india dirigido por Jagermath Lachmon, que actualmente es el Partido Progresista de la Reforma. Todos los partidos asumieron la importancia del vector étnico dentro del país lo que derivó en el cultivo de estructuras clientelares que se expandieron por todos los ámbitos de la acción gubernamental, sin embargo no asumieron la importancia de las Fuerzas Armadas como cuerpo dotado de una identidad corporativa muy marcada que provenía de la época de dominación holandesa cuando se conformó el batallón colonial conjunto Holanda-Surinam que evolucionó hasta convertirse en el Surinamse Kirjgsmacht (Ejército de Surinam). ${ }^{30}$

La desatención y la falta de control del proceso de desarrollo de un Ejército desequilibrado en su proporción suboficiales-oficiales (la proporción era de 15 a 1 a favor de los suboficiales muchos de ellos alistados en los Países Bajos) por parte del poder ejecutivo (a diferencia del marcado seguimiento que el PNC de Forbes Burnham desarrolló en Guyana con el GDF) alejó progresivamente al Ejército del Gobierno generando una desafección creciente; Henck Arron no atendió las demandas de los suboficiales del ejército en materia salarial, de destinos prolongados, en términos de dignificación de trato o derechos de sindicación de los soldados de reemplazo. En palabras de los propios suboficiales que protagonizaron el "golpe de los sargentos", "jamás se hubiera llegado tan lejos de haber sido atendidos por parte de las autoridades gubernamentales".

Como colofón al cúmulo de agravios que los suboficiales esgrimían, el Gobierno de Arron optó por enviar a la Policía civil y militar a reprimir a los efectivos que estaban organizándose sindicalmente entre las filas de las Fuerzas Armadas, arrestando y sometiendo a tres de sus dirigentes a un consejo de guerra el 20 de febrero de 1980. Cinco días después, los suboficiales derrocaron al propio Arron, lo pusieron bajo arresto y sobreseyeron la causa de sus compañeros de armas.

La conformación de la Junta Nacional Militar dio respuesta a otros problemas planteados por los suboficiales; por un lado el cese de la función del ejército como fuerza de patrullaje fronterizo en coordinación con la policía de seguridad interna. Por otro se puso fin al carácter étnico de la política de Surinam y con el alto grado de clientelismo político del modelo surinamés.

30 Chaitram Singh, "Reining in the Military Re-democratization in Suriname", in Journal of Third World Studies vol.xxIV, n. ${ }^{\circ} 1,2007$. 
La expectación que suscitó entre la población de Surinam el Golpe de estado protagonizado por "De Jongens" como fueron bautizados los dieciséis suboficiales golpistas pronto se enfrío debido a las tensiones que una sociedad étnicamente segmentada proyectaba sobre la escena política nacional.

Por un lado la comunidad criolla comenzaba a reconocer que el Golpe de Estado había depuesto a un ejecutivo que representaba mejor sus intereses que la Junta Militar Nacional. Por otro lado se produjo un severo choque entre el modelo de encuadramiento y control propugnado por las nuevas autoridades político-militares del país. El control, el seguimiento que se comenzó a realizar sobre los empleados públicos y las medidas disciplinantes impulsadas por las Fuerzas Armadas no fueron bien entendidas por una sociedad poco acostumbrada a una situación de movilización permanente de marcialidad creciente.

La popularidad de las tropas comenzó a disminuir al extenderse un concepto de "Estado opresor" entre la sociedad surinamesa, lo que para 1982 cristalizaba ya en movimientos organizados de contestación y oposición a los jóvenes militares que se sublevaron contra la política étnica que dominaba la política de Surinam de mediados de la década de los cincuenta.

Frente al descontento social que comenzaba a imperar en la ex colonia holandesa, el Estado Mayor de Bouterse organizaba su acantonamiento en el poder del país a través de movimientos en paralelo; por un lado, a principios de 1980 se desplegó una purga entre la oficialía surinamesa siendo ascendidos las figuras más cercanas a Bouterse. El propio sargento mayor se ascendió a mayor y posteriormente a coronel de las Fuerzas Armadas.

Para no generar un estado de alarma en las cancillerías aliadas (en especial en los Gobiernos de Amsterdam y Washington) Bouterse moderó las expresiones más revolucionarias, al tiempo que postergó a sus compañeros de armas más próximos al ideario marxista, algunos de los cuales fueron encarcelados toda vez que éstos renunciaron a sus postulados políticos.

De manera eficaz fueron sofocados los intentos contragolpistas que surgieron en el seno de las Fuerzas Armadas, especialmente la intento de restaurar el Gobierno civil de por parte del teniente Rambocus en marzo de 1982, que fue finalmente abortado y que terminó con el enjuiciamiento y posterior encarcelación de sus cabecillas. 
Los poderes civiles del país fueron puestos bajo el Gobierno del Consejo Militar de la Nación, que en julio de 1980 por orden expresa de Bouterse suspendió la Constitución de 1975, y disolvió el Parlamento. ${ }^{31}$

Con la disolución del parlamento y la necesidad de configurar un nuevo Gobierno, se dio paso a un modelo de organización propio de la Repúblicas Populares del campo socialista. Se constituyó una suerte de Politburó (Beleidscentrum) formado por seis miembros incluyendo al comandante Bouterse. Dicho órgano impulsaría las tareas de un Consejo de Ministros que sería presidido por el Presidente de la Corte Suprema surinamesa. Estas estructuras de Gobierno se mantendrían vigentes hasta las elecciones de 1987.32

Toda vez que la situación con las potencias aliadas de Surinam estaba normalizada, Bouterse comenzó a deslizarse hacia una nueva etapa en política exterior que le llevó a establecer relaciones con gobiernos "revolucionarios" de la región; apertura líneas de cooperación con el Gobierno de Maurice Bishop de Grenada, con el Frente Sandinista de Liberación nacional (FSLN) de Daniel Ortega y con la Cuba de Castro, de quien importó la idea de la organización de la población a través de organizaciones de masas. ${ }^{33}$

Bouterse nunca expresó un compromiso con la transformación social y, de hecho, no fueron removidos ninguna de las estructuras productivas del país ni el régimen de la propiedad fue alterado. Se producía por tanto una disociación entre el discurso público y la retórica oficial y los cambios a favor de la lucha contra las desigualdades. La desafección política ante el fraude político que comenzaba a representar el "espíritu del 25 de febrero" alcanzó su punto más alto cuando ante la imposibilidad de frenar una oleada contestaría de origen popular se procedió a la ejecución en el recinto militar de Fort Zeelandia de 15 opositores políticos el 8 de diciembre de 1982.

31 Betty Sedoc-Dahlberg, 'Suriname: The Politics of Transition from Authoritarianism to Democracy, 1988-1992", in Carlene J. Edie (ed.), Democracy in the Caribbean: Myths and Realities, Westport, 1994;. Chaitram Singh, Guyana: Politics in a Plantation Society, New York, Praeger, 1988.

32 Meel Peters, "The march of militarization in Suriname", in Anthony Payne \& Paul Sutton (eds.), Modern Caribbean Politics, Baltimore, Johns Hopkins Press, 1993, pp.47-62.

33 Se configuró el movimiento "25 de febrero" como organización al servicio de la smovilizaciones impulsadas por la cúpula militar. Se crearon los "Volkscomites", a imagen de los Comités de Defensa de la Revolución cubanos (CDR). 
Este ejercicio de represión sin precedentes, desbordó la indignación popular, lo que generó dos efectos directos; la oposición política surinamesa, profundamente fragmentada, se cohesionó y la cúpula militar tuvo que dialogar con ellos desde una posición de debilidad, fruto de su desgaste organizativo y la pérdida absoluta de crédito entre la población.

Sin embargo no sería el convulso escenario político el que provocaría la caída del Gobierno militar de Bouterse. Como ocurriera en el caso de Guyana, la economía surinamesa se situaba a principios de 1983 al borde del colapso.

Una economía como la de Surinam que se encontraba fuertemente subsidiada por las ayudas de Países Bajos. Un 20\% del PIB del país dependía de las aportaciones de la ex metrópoli. Los fondos transferidos por el gobierno de Ámsterdam para el despliegue de las instituciones de autogobierno e en 1975 no había sido aplicado a sus fines, lo que permitió ante el brutal episodio de represión de Fort Zeelandia congelar 1.959.620.00o dólares. El 10 de Diciembre de 1982, Holanda cortó toda ayuda al Gobierno de Paramaribo.

La pérdida del mecenazgo a fondo perdido que recibía la cúpula militar, unido a la debacle económica (hundimiento del precio de la bauxita en los mercados internacionales lo que provocó la pérdida de 2000 empleos en el sector extractivo, aumento del precio de los insumos básicos), provocó que para 1987, en plenos comicios presidenciales, Surinam hubiera perdido el $27 \%$ de su Producto Interior Bruto.

El Gobierno de Bouterse intentó reaccionar con un aumento de la presión fiscal sobre ciudadanos y empresas lo que generó una batería de huelgas sectoriales y generales en todo el país que, con cierta audacia por parte de la oposición política, se enlazaron demandas de carácter no laboral sino político pues al tiempo que se reclamaba el fin de la asfixia impositiva se reclamaba el fin del estado de excepción, la militarización social y se pedía la vuelta a un sistema donde se respetase el pluralismo político. ${ }^{34}$

Bouterse intentó a la desesperada generar un Gobierno interino de concentración nacional que le permitiera evidenciar ante el gobierno holandés que se estaba en el camino de la restauración de las libertades civiles y los derechos civiles y políticos. Sus esfuerzos no cristalizaron, si bien la cúpula militar cedió en marzo de 1987 a la creación de una comisión para la redacción

34 Brian Loveman, The Constitution of tyranny; Regimes of exception in Spanish America, Pittsburgh-London. Pittsburgh University Press, 1999, pp.101-107 
de una nueva Constitución35. Dicha comisión no pudo concluir sus trabajos de redacción al iniciarse un levantamiento armado en el Este del país a cargo de los llamados "Comandos de la Jungla" liderados por Ronnie Brunswijk, que reclamaba la vuelta al sistema democrático previo a 1980.

El alzamiento de los cimarrones contra el Gobierno militar de Bouterse derivó en un recrudecimiento de las posiciones más represoras del Gobierno de Paramaribo quien para sofocar la insurrección no dudó en ejecutar a civiles que no participaban en el levantamiento.

A pesar de la pérdida de control de áreas completas del país y de la huida de miles de surinameses como refugiados a la vecina Guyana, fue aprobada por un referéndum nacional el 30 de septiembre de 1987 una nueva Constitución. El nuevo texto constitucional sirvió de base para la convocatoria de elecciones presidenciales que se celebraron el 25 de noviembre del mismo año.

A pesar de la tímida apertura que la nueva Constitución permitía, el texto incluía el poder de veto militar sobre el Gobierno, al tiempo que se creaba el llamado "Comando Militar" que tenía como función constitucional "garantizar las condiciones en virtud de las cuales el pueblo de Surinam puede realizar y consolidar una transición pacífica a una sociedad democrática y socialmente justa”. (art.178.2, Constitución de Surinam). ${ }^{36}$

De manera paralela, la nueva Constitución creaba un Consejo de Estado que estaba facultado para anular las decisiones del poder ejecutivo, si bien la presidencia de dicho Consejo de Estado recaía en el Comandante Bouterse.

Quedaba así nuevamente dispuesta una omnipresencia del poder militar representando en Desi Bouterse quien a través del Comando Militar y del Consejo de Estado se garantizaba la subordinación del poder civil al poder militar que él encarnaba. ${ }^{37}$

35 Organization of American States, Second Report on the Human Rights Situation in Suriname, Washington, D. C. General Secretariat, Organization of American States, 1985; Annual Report of the Inter-American Commission on Human Rights, 1990-1991: Suriname, Washington, D. C., General Secretariat, Organization of American States, 1991.

36 Constitution of Suriname, 1987. www.constituion.org/cons/suriname.htm.

37 El ejemplo más acabado de dicha subordinación se produjo a raíz de los incidentes del aeropuerto holandés de Schipol donde el Gobierno holandés negó a Bouterse la posibilidad de entrevistarse con medios de comunicación locales. La reacción de los militares surinameses ante la tímida reacción del Gobierno de Surinam fue destituir al Gobierno en pleno en diciembre de 
En un contexto de creciente aislamiento regional e internacional, el 25 de mayo de 1991, la cúpula militar convocó elecciones presidenciales que fueron ganadas por una coalición de partidos que respondían a intereses sectoriales étnicos. El nuevo Gobierno, que contaba con el apoyo explícito de Países bajos y de Estados Unidos impulsó una modificación de la Constitución para desposeer a los militares de cualquier competencia distinta de la defensa nacional y de la integridad de las fronteras del país.

Dichas medidas generaron una reacción en la cúpula militar que fue abortada gracias al desplazamiento de tropas estadounidenses, francesas y holandesas al área del sur del Mar Caribe, que iniciaron maniobras navales con un carácter claramente intimidatorio. Bajo este amparo, el Gobierno del Nuevo Frente pudo licenciar a numerosos efectivos de las Fuerzas Armadas y pasar a la reserva a altos mandos militares que eran apoyos esenciales para Bouterse. El apoyo militar brindado por EE.UU., Holanda y Francia (que llegaron a situar tropas en la vecina Guyana) y el empuje del nuevo Gobierno encabezado por Ronald Venetiaan del NPS puso fin al formato gubernamental pretoriano dirigido por Bouterse que vio progresivamente diluida su capacidad de control sobre las Fuerzas Armadas. ${ }^{38}$ Un año después de las elecciones generales, Venetiaan en un programa de largo alcance consiguió pacificar definitivamente el país alcanzando un acuerdo de paz con las guerrillas que operaban en el país que se integraron al sistema de partidos surinamés.

\section{Conclusiones}

Entre 1968 y 1992 dos formatos de gobiernos militares de similares características dominaron la escena política de la cuenca Sur del Caribe. Ambos procesos responden a un patrón común de control absoluto por parte de las Fuerzas Armadas del resto de poderes del Estado, aspirando a un control extenso de los resortes gubernamentales basando sus acciones en la minimización de los derechos civiles y políticos de la población. Si bien en el caso de Guyana, en el proceso dirigido por Forbes Burnham observamos una orientación planificada para conseguir vertebrar un poder "verde olivo" a partir de la modificación de la naturaleza de las Fuerzas Armadas, mientras en

1990.

38 Luigi R. Einaudi, "Hemisphere United against Suriname Coup”, U.s. Department of State dispacth, n. ${ }^{\circ} 2,1991$. 
Surinam asistimos a una toma del poder político por parte de las tropas de Bouterse a partir de la incorrecta gestión y deficitario entendimiento de las demandas de las Fuerzas Armadas surinamesas.

En términos de efectos sobre la región, la solidez del Gobierno del NCP de Forbes Burnham es muy superior al proyecto de Bouterse que disoció su discurso público de los actos ejecutivos que su teórico gobierno revolucionario encarnaba. Si bien ambos procesos estaban profundamente marcados por el liderazgo mesiánico de Bouterse y Burnham (algo que los asemejaba con procesos similares en el área como el caso del Gobierno de Maurice Bishop en Grenada o del FSLN en Nicaragua), ninguno de los dos consiguió alcanzar un nivel de identificación del conjunto de la sociedad con los objetivos planteados por sus gabinetes.

Pero si existe un denominador común entre ambos regímenes fue la inviabilidad de sus liderazgos de no haber mediado la construcción del mismo a partir de la ampliación del poder de las Fuerzas Armadas. En Surinam las Fuerzas Armadas multiplicaron sus efectivos por cuatro bajo el Gobierno de Bouterse. En Guyana se multiplicaron por once bajo el control de Burnham, con el consiguiente costo en términos presupuestarios y de dedicación de esfuerzos nacionales al mantenimiento de un sistema defensivo tan vasto.

Dentro de los denominadores comunes que presentan ambos Estados que vivieron bajo modelos pretorianos el deterioro de la economía fue una constante durante ambos Gobiernos; la devaluación de las monedas nacionales, el aumento de la precios fiscal y de la inflación, la emigración masiva por motivos políticos y laborales y el desequilibrio de la balanza comercial predeterminaban en el horizonte mediato la caída de ambos gobiernos ante la depauperación de las condiciones de vida de los habitantes de Guyana y Surinam y la imposibilidad de proveer por parte del Estado de los servicios públicos esenciales.

Estas razones, unidas a las sistemáticas violaciones de los derechos libertades de la población civil dibujaban razones para el estallido social en ambas naciones. Pero ha de expresarse que, sin duda, sería el cambio en la estrategia regional por parte de Estados Unidos la que aceleraría la caída de los dos gobiernos militares de la zona. El cambio de rumbo de la Administración Clinton a partir de los sucesos de Haití y la necesidad de restituir las libertades y derechos del pueblo haitiano forzando la salida del general Cedras provocó un seísmo político que alcanzó a Guyana y Surinam que por la presión coaligada de los protagonistas regionales (Países Bajos, Reino Unido, Francia, Organización 
de Estados Americanos) terminaron arrinconando a ambos regímenes sin la necesidad de desembocar en una intervención militar abierta como la desplegada en Grenada el 25 de octubre de 1983.

Para 1992 ambos Gobiernos militares habían sido desposeídos por la vía constitucional o por las urnas de sus anteriores atribuciones permitiendo que no se reeditaran experiencias militaristas en la región, permitiéndose incluso la depuración de responsabilidades judiciales de algunos miembros de dichos Gobiernos, lo que en cierta medida limita futuras tentativas golpistas por parte de Fuerzas Armadas en la región.

\section{Bibliografía}

Annual Report of the Inter-American Commission on Human Rights, 199o-1991: Suriname, Washington, D. C., General Secretariat, Organization of American States, 1991.

Beltrán, Virgilio, El Papel Político y Social de las Fuerzas Armadas en América Latina, Caracas, Monte Ávila Eds., 1970.

Brana-Shute, Gary, "Back the Barracks? Five years "Revo" in Suriname", in Journal of Interamerican Studies and world Affairs vol.28, $\mathrm{n}^{0} 1,1986$, pp.1-15.

Burnham, L. F. S., Declaration to Sophia. 14 de Diciembre de 1974. Georgetown, GPL, 1974, pp.8-9.

Burnham, L. F. S., Economic Liberation through Socialism, Georgetown, Guyana Printers Ltd., 1977.

Celis Nogueras, Carlos, Geopolítica regional; el área del Caribe, área andina y área amazónica, Caracas, Presidencia de la República, 1994.

Congress National Party, For socialism in Guyana. Political program of the People's Progressive Party, Prague, Orbis Press Agency, 1982.

Constitution of the Co-operative Republic of Guyana, Georgetown, Guyana National Lithographic Co. Ltd., 1980.

Constitution of Suriname, 1987. www.constituion.org/cons/suriname.htm.

Costa Pinto, Luis A., Nacionalismo y militarismo, México, Ed. Siglo XXI, 1970.

Daly Hayes, Margaret, "¿Cuáles son los interrogantes?. Educación en civiles en Seguridad y Defensa”, en José Olmeda, Democracias frágiles, las relaciones 
civiles-militares en el mundo Iberoamericano, Valencia, Tirant Lo Blanch, 2005 .

Diez Alegría, Manuel, Ejército y Sociedad, Madrid, Ed. Alianza, 1972.

Einaudi, Luigi R., "Hemisphere United against Suriname Coup”, U.S. Department os State dispacth, n. ${ }^{\circ} 2,1991$.

Elieuwen, Edwin, Armas y política en América Latina, Buenos Aires, Ed. Sur, 1960.

Germani, Gino y Silvert, Kalman, Structure and military intervention in Latin America, European Journal of Sociology, Cambridge, 1961.

Halperin Donghi, Tulio, Historia contemporánea de América Latina, Madrid, Alianza Ed., 1969.

Huntigton, Samuel, "New contingencies, old rules", in Joint Force Quarterly. Professional Military Journal, n⿳003 3 , Autumn, 1991.

Jagan, Cheddi, Critical Support, Straight Talk, 14 Septiembre, 1975.

Janowitz, Morris, Military Institutions and Coercion in Developing Nations, Chicago, Chicago University Press, 1977.

Johnson, John, Militares y Sociedad en América Latina, Buenos Aires, Eds., Solar Hachette, 1966.

Joxé, Alain y Cadena, Cecilia, El armamentismo de los países dependientes. El caso latinoamericano, en Estudios Internacionales n. ${ }^{\circ}$ 14, Santiago de Chile, 1970.

Lewis ,Paul H., Autoritarian regimes in Latin America; Dictators, despots and tyrants, Anse Books. Rowman \& Littlefield Publishers Inc. 2006.

Loveman, Brian, For la Patria; Politics and the Armed Forces in Latin America, Wilmington Massachusetts, E. R. Books. 1999.

Loveman, Brian, The Constitution of tyranny; Regimes of exception in Spanish America, Pittsburgh-London. Pittsburgh University Press, 1999.

Mares, David R., Violent peace; Militarized interstate bargaining in Latin America, New York, Columbia University Press, 2001.

Miguens José E.,"Una nueva metodología para el estudio de los golpes militares en Latinoamérica" en Estrategia, Buenos Aires, Ed. Eudeba, 1969.

Moskos, Charles Jr. \& Jenkens, G. H., Las Fuerzas Armadas y la Sociedad. Madrid, Alianza Universidad, 1984.

Nun, José, América Latina: la crisis hegemónica y el golpe militar, Desarrollo Económico, Buenos Aires, 1966. 
Organization of American States, Second Report on the Human Rights Situation in Suriname, Washington, D. C. General Secretariat, Organization of American States, 1985.

Parsons, Talcott, Bales, Robert F. y Shils, Edward A., Apuntes sobre la teoría de la acción, Buenos Aires, Ed. Amorrortu, 1970.

Peters Meel, "The march of militarization in Suriname", in Anthony Payne \& Paul Sutton (eds.), Modern Caribbean Politics, Baltimore, Johns Hopkins Press, 1993.

Sedoc Dahlberg, Betty, "Interest Groups and the Military Regime in Suriname", in Alma H. Young and Phillips Dion (eds), Militarization in the Non-Hispanic Caribbean, Boulder, Lynne Rienner Publishers, Inc., 1986.

Sedoc-Dahlberg, Betty, "'Suriname: The Politics of Transition from Authoritarianism to Democracy, 1988-1992", in Carlene J. Edie (ed.), Democracy in the Caribbean: Myths and Realities, Westport, 1994.

Singh, Chaitram, Guyana: Politics in a Plantation Society, New York, Praeger, 1988.

Singh, Chaitram, "Ethnic Guardians: The Role of the Military in Guyana's Politics", in The Journal of Developing Societies, vol.IX, 1993.

Singh, Chaitram, "Reining in the Military Re-democratization in Suriname", in Journal of Third World Studies vol.XXIV, n. ${ }^{\circ} 1,2007$.

World Bank, Guyana: A Framework for Recovery, Washington D. C., The World Bank, 1985 . 